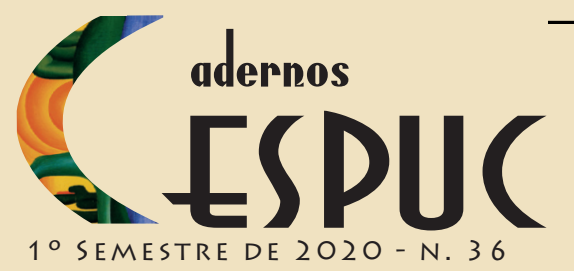

\title{
VOZES ININTELIGÍVEIS E SILÊNCIOS ORAIS: EPISTEMOLOGIAS DO SUL EM RAP GLOBAL
}

\author{
Jefferson Ubiratan de Araújo Medeiros*
}

\begin{abstract}
Resumo
Rap global (OESTE [SANTOS] 2010) é um livro de poemas publicado por Boaventura de Sousa Santos sob o pseudônimo de Queni N. S. L. Oeste. O meu intento nesse artigo é compreender, por meio da leitura e fruição desse objeto literário, como se dá o seu processo de instanciação e encenação enunciativa. Defendo que tal processo, na obra em foco, engendra a produção de geografias discursivas. A partir do exame de alguns trechos do rapoema de Santos pretendo evidenciar a relação de tais geografias com os conceitos cunhados pelo sociólogo, a saber, a "tradução intercultural" e a "ecologia de saberes", ambos integrados às "epistemologias do Sul", do sociólogo português.
\end{abstract}

Palavras-chave: Rap global. Boaventura de Sousa Santos. Encenação enunciativa. Geografias discursivas. Epistemologias do Sul.

\section{UNINTELLIGIBLE VOICES AND ORAL SILENCES: EPISTEMOLOGIAS DO SUL IN RAP GLOBAL}

Abstract

Rap global (OESTE [SANTOS] 2010) is a book of poems published by Boaventura de Sousa Santos under the pseudonym of Queni N. S. L. Oeste. My intention in this article is to understand, through the reading and enjoyment of this literary object, how it takes place in its process of instantiation and enunciative staging. I argue that such a process, in the work in focus, engenders the production of discursive geographies. Based on an examination of some excerpts from Santos' rapoema, I intend to highlight the relationship of such geographies with the concepts coined by the sociologist, namely, the "intercultural translation" and the "ecology of knowledge", both integrated into the "epistemologias do Sul", of the Portuguese sociologist.

Keywords: Rap Global. Boaventura de Sousa Santos. Enunciative staging. Discursive geographies. Epistemologias do Sul.

Recebido em 21/05/2020.

Aceito em 23/07/2020.

"Pontifícia Universidade Católica de Minas Gerais. Mestre em Literaturas de Língua Portuguesa. ORCID: https://orcid. org/0000-0003-0422-1268. 


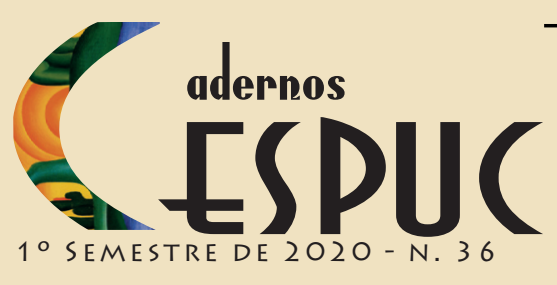

\section{Jerterson Ubiratan de Araújo mideiros}

\section{Introdução}

Toda obra literária é antes de mais nada uma espécie de objeto, de objeto construído; e é grande o poder humanizador desta construção, enquanto construção. Antonio Candido, Direito a Literatura.

[...] compôs o texto a partir da audição obsessiva de vozes ininteligíveis e de infinitos silêncios orais. Boaventura de Sousa Santos, Texto de apresentação de Rap global.

O perfil fictício de Queni N. S. L. Oeste encena o par que Santos, na apresentação de Rap global (OESTE [SANTOS] 2010), afirma ter ouvido incessantemente para elaborar a obra: "vozes ininteligíveis" e "infinitos silêncios orais". As "vozes ininteligíveis" se fazem presentes nas produções dos indignados pela não realização das promessas dos "ideais modernos" como a democracia e os direitos humanos. ${ }^{1}$ Essas produções, sempre proveniente das margens, atualmente (mas não somente) são o hip-hop, as batalhas de Freestyle, os movimentos de Slam Poetry, o funk consciente. As vozes ininteligíveis são, portanto, as vozes do lado mais fraco de cada sociedade. Por sua vez, os infinitos silêncios orais, ficam evidentes quando notamos o sofrimento dos refugiados, ou para racismo que não acabou, mesmo com a extinção do colonialismo como forma de dominação entre países. Os silêncios orais são os gritos surdos provenientes das vozes dos vencidos.

A montagem da obra Rap global, posta em ação pelo perfil fictício de Queni N. S. L. Oeste, é a grande responsável pelo povoamento da voz do jovem rapper, que encarna, como aponto acima, tanto "vozes ininteligíveis" quanto os "infinitos silêncios orais". Por isso mesmo, antes do exame dos enunciados, quero, como ponto de partida, lançar luzes sobre o jogo autoral composto por Santos e especular a respeito de "quem é" e "de onde provém a construção" Queni N. S. L. Oeste.

Quem assina o texto é Queni N. S. L Oeste, mas é possível constatar na primeira nota de rodapé do livro, colocada ao lado do nome de Santos em sua assinatura no texto de apresentação, uma pequena explicação a respeito da atribuição da autoria da obra em foco: "Boaventura de Souza Santos, além de escrever a apresentação, compôs o texto a partir da audição obsessiva de vozes ininteligíveis e de infinitos silêncios orais" (SANTOS, 2010a, p. 6).

Queni Oeste, o enunciador, produto portanto, da "audição obsessiva de vozes ininteligíveis e de infinitos silêncios orais" nos é dado por Santos como um jovem rapper do Barreiro, gueto da região metropolitana de Lisboa, e filho de Antero Silvino, "um mulato angolano" (2010a, p. 6), personagem fictício declaradamente tomado de empréstimo do romance de Manuel Rui, A casa do rio (2007).

Assim sendo, na composição do processo de instanciação enunciativa proposto por Santos em Rap global (2010) é fulcral a costura genética, política e social que reveste o perfil de Antero, um refugiado angolano, apátrida, que é dado como pai de Queni. Antero, é um índice ${ }^{1}$ Uma versão mais aprofundada do estudo aqui apresentado se encontra na Dissertação de Mestrado defendida no Programa de Pós-graduação em Letras da PUC Minas, no dia 9 de maio de 2019. O trabalho se encontra disponível no link: http://www.biblioteca.pucminas.br/teses/Letras_JeffersonUbiratanDeAraujoMedeiros_7646.pdf 
que agrega à persona do jovem uma sofrida história prévia, já que ele encarna a forçada diáspora angolana de $1975,{ }^{2}$ fenômeno que se deu a partir de um turbulento processo de independência no qual milhares como Antero saíram do continente africano para os guetos de Lisboa, Portugal.

Confinado num subúrbio apinhado de gente e de racismo, Antero nunca recuperou do trauma do desterro, da falta das paisagens paradas e imensas do planalto, das chuvas torrenciais vergando o céu e as árvores e das picadas infinitas por onde o seu camião levava os mimos da cidade para o mato. (SANTOS, 2010, p. 6).

Nesse excerto do texto de apresentação, estão arranjados, recursivamente, por Santos, índices que remetem diretamente ao que é narrado no romance de Manuel Rui: as paisagens do "planalto" do Huambo, as "chuvas torrenciais vergando o céu" e o "camião". O "camião" é, inclusive, o mote sob o qual se desenrola boa parte das ações iniciais da narração do romance de A casa do rio (2007).

Há que se acrescentar que, no texto de apresentação de Rap global (2010), o enunciador Queni Oeste, de maneira nada menos que antropofágica, é ainda construído com base no rapper norte-americano Kanye Omari West. Tanto é que Santos afirma,

São as primícias de uma obra promissora, se os tormentos e neuroses da família e seus não acabarem por se sobrepor a todo o resto. A leitura desta rapoesia só pode ser feita tendo no ouvido o ritmo da música rap. Aconselho que se esteja a ouvir um dos CDs anteriores do Queni enquanto se lê este texto. (SANTOS, 2010a, p. 7).

Kanye West, portanto, é mais uma personalidade que compõe a de Queni. Do ano de 2007, quando lança o primeiro disco de sua carreira como cantor, ${ }^{3}$ até 2010, ano do lançamento de Rap global (2010), Kanye era tido como uma grande novidade, seja nos temas que manejava nas músicas, seja na construção de seu som. Santos, atento à paisagem musical do rap, acompanhou os passos desse proeminente artista que falava de Jesus, de diamantes de sangue, falava também da violência e das drogas, mas de maneira sensível e inovadora.

Tendo em mente a mistura acima exposta, a partir desse momento, farei um pequeno exame do processo de encenação e instanciação enunciativa concernente à obra em foco. A ideia é testar a hipótese de que os espaços de referência construídos na fala habitada de Queni são reveladores de geografias discursivas dos oprimidos. Posteriormente, e com mais excertos em exame, pretendo evidenciar a relação de tais geografias com os conceitos cunhados pelo sociólogo, a saber, a "tradução intercultural" e a "ecologia de saberes", ambos integrados às "epistemologias do sul", do sociólogo português

${ }^{2} \mathrm{~A}$ respeito das pontes aéreas, ver, por exemplo, uma longa reportagem feita pelo Jornal Público (Portugal) com pessoas que viveram os fatos. https://www.publico.pt/2017/11/12/sociedade/noticia/destino-luanda-a-tripulacao-que-ajudou-a-erguer-a-ponte-aerea-de-1975-1791835

${ }^{3}$ Anteriormente era reconhecido apenas como produtor musical. 




\section{Jetrcrson Ubiratan de Araújo medeiros}

\section{Geografias discursivas no Rap global}

Para se conhecer um objeto, não se deve portanto desprezar nenhuma das analogias que o ligam às coisas e aos seres. François Jacob, A lógica da vida.

Rap global (2010) põe em ato a tríade Eu, Tu, Espaço de referência, que compõe o "aparelho formal da enunciação" (BENVENISTE, 2006, p. 81-90) e preconiza a organização da cena enunciativa. Esse "aparelho", é acionado toda vez que alguém põe em ato a sua fala. A cada tomada de "palavra" se tem um ato novo e, portanto, sui generis. Para Benveniste, isso ocorre até no chamado monólogo interior, quando o eu projeta o seu interlocutor.

No Rap global (2010), as cenas enunciativas vão sendo integradas ao fluxo do poema e a integração dessas cenas, como afirma Per Aagent Brandt (2012), forma uma "cascata de sentido". Dessas cenas em "cascata" se pode apreender apenas constelações de sentido, não o sentido estrito, isolado, limpo, daí o resultante final (gestáltico) ser maior que a simples soma das partes. Assim, o sentido das palavras que são usadas pelo escritor para esculpir as cenas deve ser entendido em associação, sempre, ao contexto temporo-espacial da(s) cena(s).

No exame de um trecho inicial de Rap global (2010), a metáfora da "máquina diária" atua construindo um espaço de referência que remete ao movimento de uma repetição industrial,

porra não há gritos
no máximo há notícias
a máquina é diária
do esquecimento
ao cimento

(OESTE [SANTOS], 2010, p. 9)

Observamos, então, na voz de Queni a instanciação de um espaço semiótico, onde o frame da ausência de gritos é contraposto ao frame do ato de noticiar ("no máximo há notícias"). O cruzamento dos dois frames dá ao leitor coordenadas para construir um entendimento de que o "eu poético" fala de um espaço onde o apagamento das vozes seria fruto de um engendramento midiático. Progredindo na escuta da voz de Queni, podemos inferir que a metáfora "máquina é diária", nesse contexto de leitura, refere-se a cenas enunciativas comuns ao jornalismo, que, por meio de seus processos, sequenciais, repetitivos, operariam a solidificação do esquecimento, silenciando minorias ou elegendo narrativas triunfantes e, por isso, hegemônicas.

O processo enunciativo é instaurado por Santos na voz de Queni N. S. L. Oeste como uma discursivização: "criação, numa, e única, instância enunciativa, de um espaço de referenciação $\mathrm{X}$, que integre, recursivamente, numa rede, com todos os espaços de referenciação instituídos no processamento discursivo" (Nascimento e Oliveira, 2004, p. 288). 
Vejamos como se dá a instanciação enunciativa das três principais facetas de Santos no Rap global (2010):

\section{FIGURA 1 - Instâncias enunciativas.}

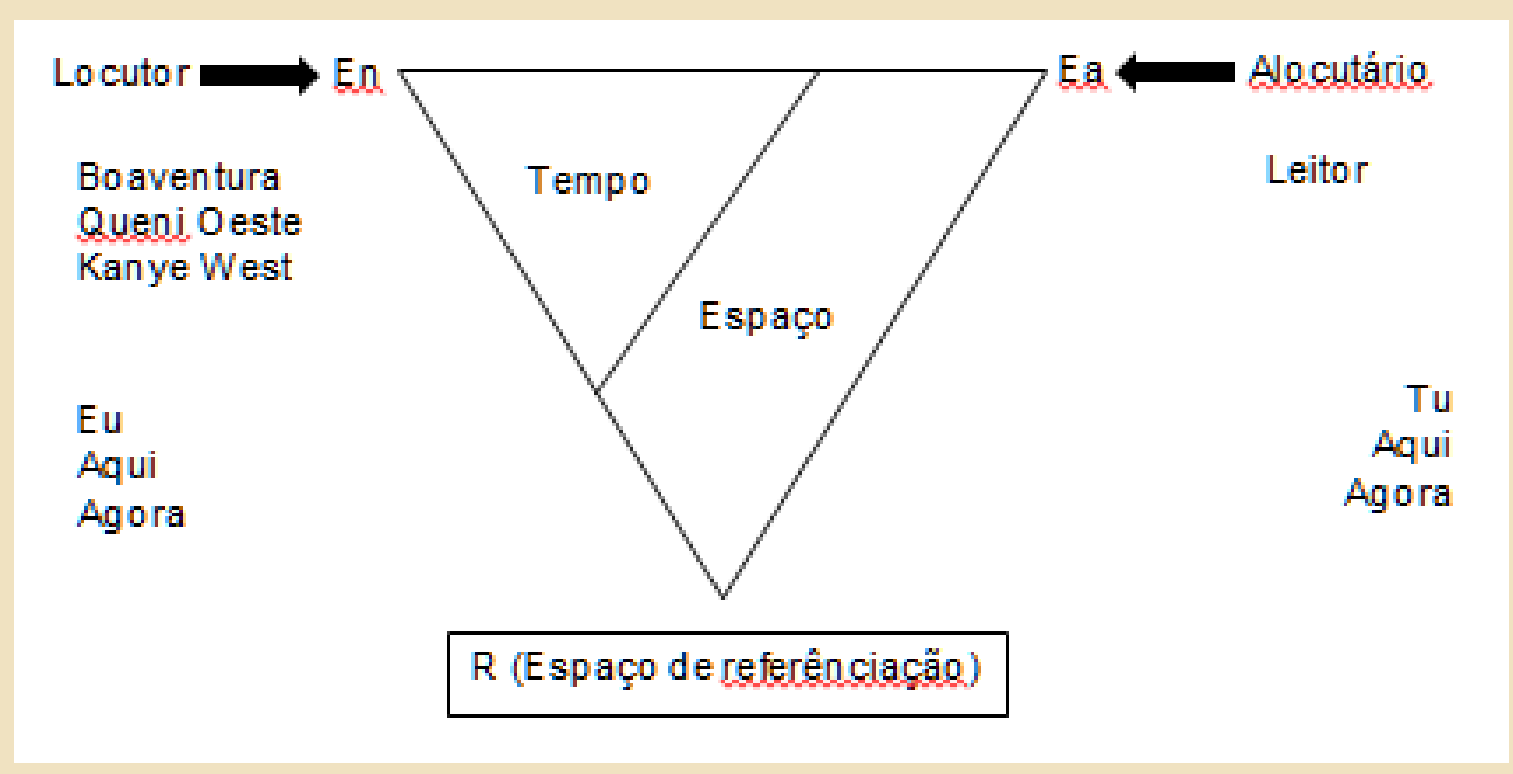

Fonte: Adaptado de Nascimento e Oliveira (2004)

No diagrama acima, podemos perceber que o polo do "locutor" (Santos) enuncia o polo do alocutário (leitor), usando para isso a máscara de Queni em seus desdobramentos temporoespaciais. $\mathrm{O}$ alocutário segue as pistas emitidas (delegadas) com vistas construir o espaço "R" (o espaço de referenciação) em sua mente. Portanto, são espaços mentais que, integrados, vão agregando sentido à cena de atenção compartilhada, que, assim, se desdobra em outras cenas. Esses espaços mentais, são delimitáveis (TALMY, 1996) como uma "porção de significado" (ECO, 1974, p. 60) e emergem da vivência do ser humano evidenciando uma estrutura conceitual interna, como vimos no exemplo da "máquina é diária", trabalhado anteriormente. Este nos possibilitou considerar que o "jornalismo", ao invés de denunciar e expor, pode se prestar a silenciar pontos de vista outros. Vale ressaltar, ainda nos referindo aos versos sobre a "máquina diária", que a estrofe é finalizada com a palavra "cimento", que, por sua vez, está contida na palavra "esquecimento". Na forma como figuram no poema - "do esquecimento/ao cimento" -, as palavras fazem com que irrompa no discurso o sentido da perda, da fragmentação e da cristalização do esquecimento, simbolizado pelo silenciamento das vozes, ou, mais ainda, do próprio espaço social nas relações de poder que o compõem.

Aponto como um exemplo de geografia discursiva uma espécie de refrão, que com sutis variações, abre cada um dos vinte e um blocos textuais que compõem o Rap global (2010).

jesus caminha

caminha com alguém

que pode ser ninguém

alah caminha 
caminha com alguém

en las ramblas de granada

e não acontece nada

(OESTE [SANTOS], 2010, p.9)

No verso "jesus caminha", notamos uma remissão direta ao grande sucesso de Kanye West, "Jesus Walks" (2004). Essa canção, prêmio "Grammy de Melhor Canção de Rap"4 no ano de 2005, está presente no álbum de estreia de Kanye, "The College Dropout" (2004), agraciado com o disco de ouro nos Estados Unidos. Nos versos do Queni construídos por Santos, as figuras de "jesus" e de "alah" no ato de caminhar, ao lado dos pronomes indefinidos "alguém" e "ninguém", são deslocadas de seu lugar de divindades que regeriam a vida humana. Uma típica contrafactualiade, que, pela fricção que gera (ninguém/alguém), se torna construtora de espaços também indeterminados com orientação para o nada. Já que não existe espaço determinado, existem formações com as quais os seres humanos constroem relações: a alusão às "ramblas de granada" 5 e sua multiculturalidade são elementos que evidenciam a perspicácia da montagem de Rap global (2010). No caso do excerto em foco, o espaço construído na voz do jovem rapper encena, pois, uma busca infrutífera por soluções no espaço geográfico palco da disputa entre mouros e espanhóis através dos tempos.

$\mathrm{Na}$ instauração e integração desses espaços mentais vale lembrar, possuidores de status fenomenológico, ${ }^{6}$ nascem as geografias, ou seja, espaços mentais criados a partir da perspectivação de instâncias enunciativas. É como se a cada tomada da palavra, a partir da perspectiva de um falante, a produção dessas geografias discursivas emergisse no on-line da instanciação (ação/estado) do sujeito, no "aqui/agora", em que espaços e sujeitos on-line originam/integram/referenciam espaços off-line no processamento discursivo. Tais espaços mentais carregam consigo os fenômenos físicos, biológicos e humanos que neles ocorrem, suas causas e relações num dado espaço/tempo, como no exemplo do refrão estruturado no espaço de referência da praça Bib-rambla.

Em um processo antropofágico da mente (Cf. WALTY, 2018), Santos se vale de sua experiência de poeta e de sociólogo para construir os espaços de referência que emergem do discurso de Queni. Defendemos que esse tipo de apropriação das características de alguém, com vistas a construir um outro ser, ainda que de papel, como os personagens literários, é derivado de um processo antropofágico da mente. O caráter antropofágico da mente pode ser reforçado remontando a Aristóteles e lendo no seu conceito de mimese, ou seja, imitação, um

${ }^{4}$ Das dez indicações que teve, Kanye faturou três prêmios Grammy em 2005. Kanye é maior detentor de prêmios Grammy da atualidade com 22 estatuetas.

5 A Praça Bib-Rambla ou Bibarrambla, é uma praça histórica da cidade de Granada, na Espanha, cuja origem remonta a um período de dominação árabe do território. A praça teve um papel importante na cidade devido à sua proximidade com núcleo comercial e mercantil da capital do reino muçulmano granadino, sua presença nos versos de Queni, portanto, deve estar ligada ao símbolo de espaço híbrido - de convivência entre credos -, que representa. Evocando a praça da cidade de Granada, o autor parece querer um índice partilhável entre o mundo muçulmano e o mundo cristão. Um reforço para a ideia de que o autor busca um ponto comum entre cristão e muçulmanos é que, após a conquista cristã da cidade (1492), a praça foi também palco de autos de fé da Inquisição, onde foi decidido o destino de muitos cidadãos e onde foram queimados muitos manuscritos árabes, particularmente cópias do Alcorão. Estima-se que foram queimadas cerca de um milhão de obras em Granada. (PLAZA BIBARRAMBLA. In: Guide to Granada. Disponível em: <www.granadamap.com>. Acesso em 7 Mar. 2019).

${ }^{6}$ Um cenário referencial ao mesmo tempo topológico e construtor de espaços discursivos. 


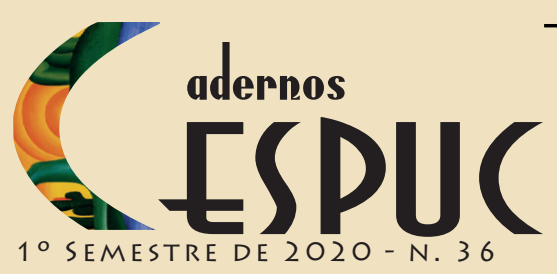

\title{
Jerterson Ubiratan de Araũjo mideiros
}

rastro avant la lettre da antropofagia.

Essa antropofagia mental, constante anexação do outro, em Rap global (2010), é posta em ação, como evidenciado, pela interação dialógica própria dos seres humanos. Nessa interação, somos capazes de partilhar a produção de sentido. A antropofagia, enquanto conceito, pode revelar-se demasiadamente produtiva para se pensar as relações de poder do colonialismo, temática fulcral na construção de Queni.

A despeito da ideia de desmantelamento com que o conceito de antropofagia costuma aparecer no discurso "civilizado" sobre a "barbárie", o ato canibal pode ser visto como uma transubstanciação. Sob a perspectiva oswaldiana e selvagem, a antropofagia prevê um quadro no qual aquele que é o devorador se altera no devorado. A "morte" e "devoração" do outro recriam o próprio; dentro dessa perspectiva, o discurso ressentido das relações coloniais, por exemplo, torna-se discurso produtivo de identidades (ALMEIDA, 2005). Assim sendo, o canibal tornase o sujeito transformador, do social e do coletivo, que Oswald de Andrade preconizou em "O manifesto antropofágo", publicado em 1928. Tal sujeito assim, sai da "condição de objeto passivo", para ser o prumo sob o qual Andrade constrói sua releitura não só da história do Brasil, mas também da própria tradição ocidental.

O conceito de antropofagia do autor de Manifesto da Poesia Pau-Brasil, de 1924, ${ }^{7}$ vem sendo retomado com valência e aceitação por parte de pensadores de diversas áreas do conhecimento, sobretudo dos estudos pós-coloniais no Sul global. Pensadores oriundos desses países ou que neles empreendem pesquisas, dos quais Santos é exemplo, diuturnamente citam, direta ou indiretamente, o "Manifesto Antropofágo" em suas construções conceituais.

O que acontece é que as referências se cruzam quando um "outro", um sujeito criador, como Santos, toma para si ações praticadas por um intelectual moderno (Oswald). Da integração dessas referências, nasce a figura de Queni, evidenciando que a antropofagia e outros conceitos engendrados pelos discursos chamados periféricos têm causado forte influência na ciência tradicional e na criatividade mundial. Isso porque, mais que a assimilação do que é necessário da cultura do outro e o descarte daquilo que não interessa, o que se observa é a ação integradora das culturas porque fruto da ação integradora da mente humana.

\section{Epistemologias do Sul}

\author{
Uma epistemologia do Sul assenta em três orientações: \\ Aprender que existe o Sul; \\ Aprender a ir para o Sul; \\ Aprender a partir do Sul e com o Sul \\ Boaventura de Sousa Santos, Pela Mão de Alice.
}

\footnotetext{
${ }^{7}$ A publicação de Manifesto da Poesia Pau-Brasil foi concomitante à do "Manifesto Surrealista" (1924), de André Breton, fato que denota uma certa sincronia do pensamento vanguardista brasileiro em relação ao que se discutia no continente europeu. A questão central do surrealismo, a ênfase na atuação do inconsciente na arte, descamba, no manifesto de Oswald Andrade, para um ponto central do conceito de antropofagia, a saber, o potencial humano que estava sendo destruído pelo racionalismo.
} 


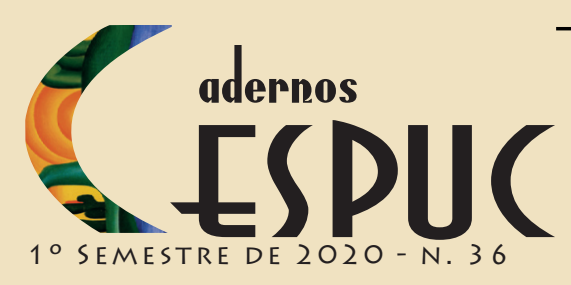

\section{Jetrebson Ubiratan de Araũjo medeiros}

Rap global (2010) é um ato criativo realizado numa lógica "de baixo para cima", falado na linguagem das ruas, dos protestos. Ele é também formado pelos gritos surdos das "vozes ininteligíveis" que se levantam contra o capitalismo e a não realização, para todos, do prometido "bem-estar social" e, ainda, pelos "infinitos silêncios orais" dos imigrantes, dos viciados, dos LGBTQ+, dos párias sociais das metrópoles modernas.

O ato criativo de Santos se processa na voz e nos corpos subalternos, em trânsito diaspórico pelo mundo, e o rap, a linguagem de confronto, fornece-lhe o substrato indignado necessário para chocar, misturar, deglutir e traduzir situações de opressão do humano pelo humano. Como por exemplo, numa perspectiva sociológica, a assonância artigo "o" + "mano" (irmão), na forma coloquial com que os rappers se tratam ("mano"), vira sinônimo de ser humano. Ser humano que migra em busca de novas terras para viver dignamente:

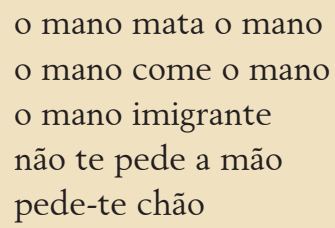

(OESTE [SANTOS], 2010, p. 61)

Ao passo que proclama a igualdade entre as pessoas (humano $=$ o mano) na sua construção linguística, o engendramento recursivo do poeta Santos atribui uma identidade humanista, com suas contradições, a Queni. Não se pode negar que tal construção seja fruto do imaginário sociológico de Santos, de sua experiência como intelectual.

Tal imaginário trespassa a persona de Queni, quando este aborda a opressão feminina perpetrada pelo hétero-patriarcado. As instituições tradicionais e o papel da mulher na organização social, por exemplo, são questionadas nos versos,

$$
\begin{aligned}
& \text { casamento } \\
& \text { gravidez } \\
& \text { filhos } \\
& \text { a ordem } \\
& \text { é arbitrária } \\
& \text { mas a desordem }
\end{aligned}
$$

(OESTE [SANTOS], 2010, p. 55).

Em outro momento, uma crítica aos lugares sociais tradicionalmente pensados como sendo "coisa de mulher" podem ser percebidos nos versos:

$$
\begin{aligned}
& \text { a eva foi o bode } \\
& \text { expiatório } \\
& \text { pra haver mães } \\
& \text { e enfermeiras } \\
& \text { telefonistas }
\end{aligned}
$$




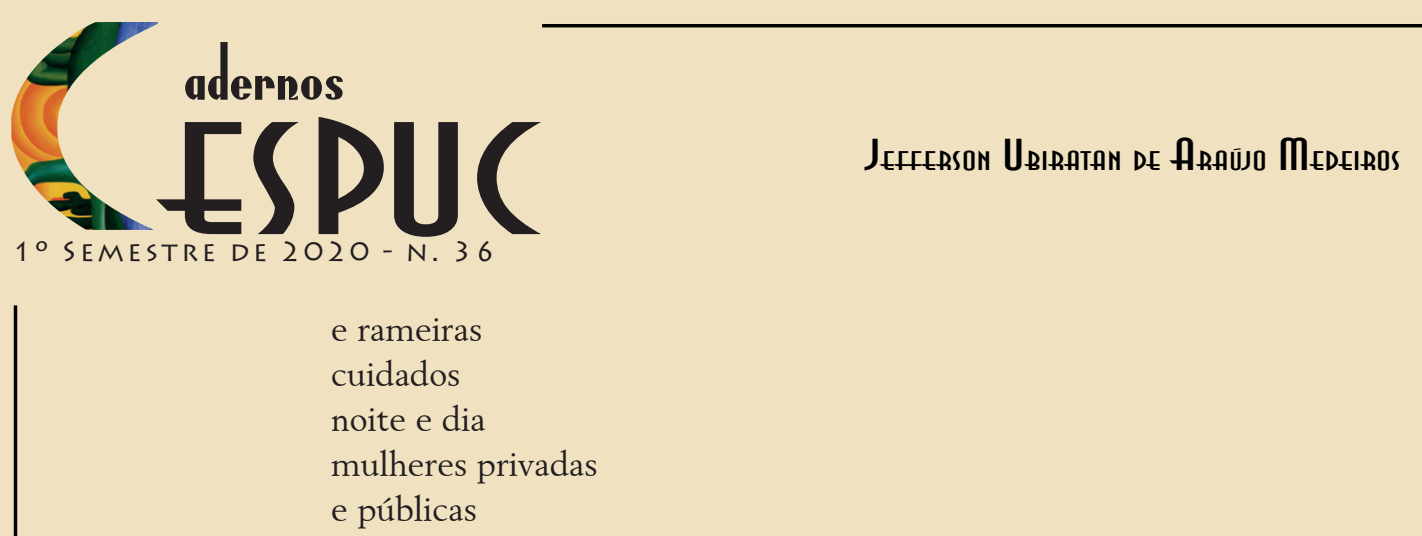

(OESTE [SANTOS], 2010, p. 21)

Da expressão, "mulheres privadas/e públicas" dos versos de Queni é possível inferir que é a essas exigências que ele se refere, pois, o corpo feminino é objeto de posse, em uso comum ou particular. Trata-se, pois de uma perpetuação e fusão das posses "casamento/gravidez/filhos/a ordem/é arbitrária".

A partir do rápido exames dos excertos acima listados, fica claro que Rap global pode ser descrito com as mesmas palavras que Santos utiliza para formular o conceito de epistemologias do Sul, a saber:

exercício de imaginação epistemológica e de imaginação democrática, com o objetivo de construir novas e plurais concepções de emancipação social sobre as ruínas da emancipação social automática do projeto moderno (SANTOS, 2002, p, 273-274).

As epistemologias do Sul são o grande empreendimento teórico de Boaventura de Souza Santos. Esse conceito aporta a ideia de encarar o Sul como uma metáfora das injustiças sociais (racismo, dívidas com o FMI etc) e cognitivas (desvalorização de suas tradições e saberes) com que os povos que formam esse bloco sofrem, mesmo após a conquista da Independência e o consequente fim formal da exploração colonial.

A ação social, a luta, é uma constante na vida dos vencidos, dos colonizados, dos oprimidos. Santos pretende ser um intelectual, poeta, ativista que problematiza a ação social e fornece operadores à audiência, para que em cada um de seus sujeitos formadores, emerja um efeito emancipatório.

As epistemologias do Sul invocam necessariamente antologias outras (revelando modos de ser diferentes, os dos povos oprimidos e silenciados, povos que têm sido radicalmente excluídos dos modos dominantes de ser e de conhecer). Dado que esses sujeitos são produzidos como ausentes através de relações de poder muito desiguais, resgatá-los é um gesto eminentemente político. As epistemologias do Sul incidem em processos cognitivos relacionados com o significado, a justificação e a orientação na luta disponibilizados pelos que resistem e se revoltam contra a opressão. (SANTOS, 2018, p. 21).

O objetivo das epistemologias do Sul é deixar de existir, deixar de ser necessária. Sim, pois assim sendo, significaria que os sujeitos de países periféricos não são mais produzidos como ausência, que seus conhecimentos e práticas sociais não são tidas como magia, selvageria etc. Significaria, por fim, que a igualdade ontológica efetivamente solapou o racismo.

Tal objetivo somente pode ser realizado se valorando as artesanias das formas de vida, ou seja, o modo natural com que os saberes se desenvolvem no enfrentamento de necessidades por parte dos diferentes grupamentos humanos. Daí o fato de Rap global (2010) ser uma 
efetivação das epistemologias do Sul, pois trata-se de um projeto que implica no cruzamento não apenas de diferentes tradições teóricas, mas também de diferentes culturas e formas de interação entre a cultura e o conhecimento, bem como entre o conhecimento científico e o conhecimento não-científico.

Esse cruzamento de formas de interação entre a cultura e o conhecimento se manifesta, por exemplo, no fechamento dos blocos textuais de Rap global (2010), onde lemos, "Real life tribal brother improve comedy" (várias páginas). Essa seria na batida do rap, uma maneira de Queni gritar aos cinco ventos (o quinto é interno), como a vida real desrealizada, fractalizada que é, se reflete nas desigualdades (das comunidades) globais como num jogo de espelhos. Todavia, muito embora todos sejamos membros da mesma "tribo humana", a diversidade interna do nosso tecido social, arranjos genótipo/fenótipo, incrementa a comédia que seria a nossa vida no planeta Terra. A comédia, em tal contexto, seria uma referência ao gesto de dissimulação, farsa, fingimento, hipocrisia, teatro incrustados nas relações de exploração do homem pelo homem. Não é por mero acaso que "Real life / tribal brother / improve comedy" é o gesto sonoro, performado em estribilho, que fecha cada bloco textual da rapoesia de Queni. É contra as desigualdades e a opressão entre os irmãos de "tribo", a exploração do homem pelo homem, que Queni grita, encenando o locus fenomenológico enunciativo daqueles que sublimam os seus gritos dia após dia.

Queni é permeado por "sujeitos produzidos como ausentes pela assimetria das relações de poder do espaço globalizado. Cada território, com suas relações e práticas sociais, é encenado em apropriações e criações de espaços de referência, traduzidos por sujeitos-tradutores que podem ser referidos por meio de epítetos, posturas, perguntas essenciais, relações opressivas, libertadoras etc.

\section{Tradução e Ecologia de Saberes}

Queni encena, evoca, apresenta e também se performa como tradutor no Rap global (2010). Por isso mesmo, um vasto rol de tradutores se encontra disperso pela obra: "tradutorescubanos-descalços" (p.11); "tradutores-sylvianos" (p. 18); "tradutores-sem-memória" (p. 22); "tradutores-toupeiras" (p. 30); "tradutores-renegados" (p. 31); "tradutores-surdo-mudos" (p. 34); "translators-tradutores" (p. 39); "tradutores-apátridas" (p. 43); "tradutores-encenadores" (p. 45); "tradutores-salvadores" (p. 49); "tradutores-sextus-propertius" (p. 49); "tradutoresde-óbvios-pedantes" (p. 51); "tradutores-carpinteiros por favor" (p.53); "tradutores-suicidas" (p. 58); "tradutores-de-aniversários -ao-contrário" (p. 60); "tradutores-sem-nexo" (p. 61); "tradutores-vagabundos" (p. 62); "tradutores-seguradores” (p. 63); "tradutores-limbodancers" (p. 75); "tradutores-para-quê se o limbo dancer dança" (p.75); "tradutores-exctasy" (p. 78); "tradutores-comunas" (p. 82); "tradutores-pra-quê por enfado" (p. 83); "tradutoresacompanhantes" (p. 85); "tradutores-de-cavalos" (p. 89); "tradutores-cavalos" (p. 89); "tradutores-de-argamassa” (p. 90).

As figurações dos tradutores se dão tanto no sentido opressivo como no libertador. Boaventura afirma que o trabalho de tradução 
é o procedimento que nos resta para dar sentido ao mundo depois de ele ter perdido o sentido e a direcção automáticos que a modernidade ocidental pretendeu conferir-lhes ao planificar a história, a sociedade e a natureza" (OESTE [SANTOS], 2002, p. 273).

A teorização em torno do trabalho de tradução intercultural no pensamento de Boaventura de Souza Santos é importante para refinar o entendimento acerca do exercício criativo da construção do enunciador Queni N. S. L. Oeste e, por conseguinte, da sua discursivização em Rap global (2010). Segundo Boaventura de Souza Santos, "uma vez que os campos da arte e da estética foram menos colonizados por ideais limitadores, eles proporcionaram uma maior abertura para experimentações e tensionamento de limites" (SANTOS, 2010b). A linguagem do rap, dessa feita, se encaixou como uma luva no projeto, por ser a possibilidade de articular ao mesmo tempo as dimensões estética, política e cientifica. A criação de Queni é aquilo que Boaventura não pode ou não consegue dizer cientificamente sobre a modernidade ocidental, a partir de uma perspectiva pós-colonial, mas pode fazê-lo por via literária, poiética e poética.

Com a clara intenção de construir novas e plurais concepções de emancipação social, o enunciador de Rap global (2010) faz aqui o trabalho da tradução, opera gerando inteligibilidade recíproca, conciliando diferentes lutas de oprimidos e trabalhadores, das questões de gênero, étnicas ou religiosas. O trabalho de tradução, como defendido por Santos, incide sobre os saberes e sobre as práticas (e seus agentes).

A ecologia de saberes, por sua vez, estaria, para o sociólogo português, para além da transdiciplinaridade, pois não parte da disciplinarização (compartimentalização) do conhecimento, ranço positivista de engavetar em especializações cada parte de uma área do conhecimento cientifico. A construção de Queni, por tudo que a forma, nos planos genéticos, políticos e estéticos, desemboca na postura do sage, um filósofo da sagacidade, que pode ser um poeta, um contador de histórias, músico ou uma autoridade tradicional. Filósofos africanos como Odera Oruka trabalham com essa ideia de filosofia tradicional africana que escapa à armadilha etnofilosófica.

Nem todos os sábios são pensadores livres, mas alguns combinam a qualidade convencional da sabedoria com o atributo dialético e crítico do pensamento filosófico livre. A "filosofia da sagacidade", portanto, é apenas o pensamento crítico e reflexivo de tais sábios. Difere fundamentalmente da etnofilosofia, na medida em que é individualista e dialética. É um pensamento ou reflexão de vários pensadores individuais conhecidos ou nomeados, não uma filosofia popular e, ao contrário do último, é rigoroso e filosófico no sentido estrito. (ORUKA, 2002, p. 5).

O que há de rigor filosófico na postura ululante de Queni provém da mente de Santos, que faz de seu construto um efetivo exercício de ecologia de saberes. Manuel Rui é o índice de uma retomada que desenvolve o caráter de sagacidade de Queni. Costurar a história de seu enunciador a de outro sujeito ficcional é uma maneira de afluir. É somando os saberes, os sons e sabores da terra manejados por Antero à genética de sua personagem que Santos compõe seu enunciador rapper tradutor intercultural. Encarando Queni como organismo sensório complexo, podemos estender a ele o aspecto de hereditariedade que François Jacob, descreve em A Lógica da Vida (1982): 
O organismo torna-se assim a realização de um programa prescrito pela hereditariedade. A intenção de uma Psiché foi substituída pela tradução de uma mensagem. O ser vivo representa certamente a execução de um projeto, mas que não foi concebido por Inteligência alguma. Ele tende a um objetivo, mas que não foi escolhido por vontade alguma. Este objetivo é preparar para a geração seguinte um programa idêntico. É reproduzir-se. (JACOB, 1982, p.12).

O jovem rapper é, então, o reproduto de dores e cicatrizes de Antero, seu pai. No entanto, a figura de Kanye West, como um artista que rejeitou a formação escolar para realizar sua formação na ação do discurso do rap, também está eclipsada na persona de Queni. Kanye West, antes do lançamento de Rap global (2010) por Santos, lançou três discos que dialogam com a lógica do saber para além da transdisciplinaridade, como propõe a ecologia de saberes: "The College Dropout", em 2004, passando por Late "Registration", de 2005 e "Graduation" (2007). Notemos que cada álbum vai exibindo, na ação e no registro do discurso do rap, a formação desse artista. Curiosamente, a "School of the Art Institute" de Chicago, concedeulhe um Doutorado honorário vinte anos depois do abandono da "Chicago American University of Arts". 8

A ecologia de saberes proposta por Boaventura critica a lógica da monocultura do saber e do rigor científicos. Essa lógica deveria ser questionada pela "identificação de outros saberes e de outros critérios de rigor que operam credivelmente em contextos e práticas sociais declarados não-existentes" (SANTOS, 2002, p. 250). Para isso, ela prevê articulação de diferentes fontes de conhecimento, científicos e populares, com vistas a fortalecer as ações coletivas. A articulação de saberes é visivelmente um objetivo que Boaventura procura alcançar com a construção da voz de Queni, dado que ele é a skin in the game de um jovem angolano, filho do desterro, um retornado a um país que não é seu.

A ecologia de saberes torna-se, voltando ao conceito, mais que uma transdisciplinaridade, pois rompe com as barreiras do saber acadêmico ao dar voz à experiência que o saber cientificista (positivista, sobretudo) despreza. O ato de comparar torna-se, nesse quadro, inevitável à exploração dos próprios saberes, a seus limites e possibilidades. Dois fatores dificultam essa comparação: a assimetria entre saberes ou a diferença epistemológica (2009, p. 468).

Não vamos nos aprofundar, neste momento, nos conceitos de assimetria e diferença epistemológica por limitações de espaço. Por ora, vale destacar que, no quadro teórico proposto por Boaventura (HYSSA, 2011), a transdisciplinaridade somente se sustenta se se tornar, ou ter como meta ser uma ecologia de saberes. Pois, do contrário, não se rompe com a primazia que o conhecimento científico ocidental sobre outros saberes produzidos a partir das vivências dos povos vencidos.

\section{Conclusão}

Em suma, a poesia de Santos, certamente, está afastada da ideia tradicional do poeta filósofo/cientista, aquele que cria ou retoma em versos preceitos da doutrina, reparando

8 (Disponível em: <https://f5.folha.uol.com.br/celebridades/2015/05/1627952-kanye-west-recebe-diploma-honorario-de-doutorado.shtml>. Acesso em: 10 Mar. 2019). 
com a perícia do verbo ornamentado uma suposta esterilidade estética. Longe de negar suas intimidades com a ciência, a poesia de Santos propõe uma singular mistura do mais mundano ao mais abstrato, de tal maneira que faz ecoar uma certa estranheza familiar em cada verso.

Por mais absurdas que pareçam algumas imagens, um exercício de empatia sempre se realiza sobre leitor de Rap global (2010). Esse exercício empático que acomete o leitor comprova que no processamento enunciativo, mais do que encenar, o ser humano é capaz de se encenar encenando, e daí "atribuir vida" a qualquer ser, mesmo que de papel, como é o caso de todos os ecos de vozes ininteligíveis e infinitos silêncios orais que habitam a fala de Queni.

Por isso mesmo, no Rap global (2010), ressaltamos o trabalho do poeta Santos com a linguagem. Esse trabalho, sem abrir mão da clareza passional dos dilemas da experiência, resgata e explora a difícil reciprocidade entre filosofia e história, entre conceito e biografia. As geografias discursivas, espaços de referência acionados pela voz habitada de Queni são a esteira por onde se desenrola esse encontro.

A proposta parece ser traduzir e proporcionar diálogos que visem as emancipações sociais das vítimas do capitalismo, do colonialismo e do patriarcado. Como demonstrado, é daí que provém a ligação do verdadeiro exercício de empatia que é Rap global (2010) com os conceitos derivados das epistemologias do sul: a tradução intercultura e a ecologia de saberes. Tal fato, faz do poema de Santos uma emulação de uma caminhada pela banda de Moebius, onde ele estaria oscilando entre as suas faces de sociólogo (cientista) e poeta (artista), sem se reduzir a nenhuma delas, rumo ao infinito da criatividade humana.

\section{Referências}

ANDRADE, Oswald de. Manifesto Antropófago. In: Revista de Antropofagia. São Paulo: [s. n.], 1928-1929. 26 fasc. 2a . Dentição (n. 1-16) publicada em uma página no Diário de São Paulo. ISSN: 0102-5104. Disponível em: https://digital.bbm.usp.br/bitstream/bbm/7064/2/ Anno.1_n.01_45000033273.pdf. Acesso em: 12 Jan. 2019.

ANDRADE, Oswald. Manifesto da Poesia Pau-Brasil. In: Correio da Manhã, 18 de março de 1924. Disponível em: <http://memoria.bn.br/pdf/089842/per089842_1924_09147.pdf>. Acesso em: 20 Jan. 2019.

BENVENISTE, E. Problemas de linguística geral II. Tradução de Eduardo Guimarães. 2. ed. Campinas, São Paulo: Pontes, 2006.

BRANDT, Per Aage. Meaning Production, Modelling Mental Architecture and Blending. 2012. (Disponível em: https://ssrn.com/abstract=2150213 or http://dx.doi.org/10.2139/ ssrn.2150213. Acesso em: set. 2018).

ECO, Humberto. A forma do conteúdo. Tradução de Pérola de Carvalho. São Paulo: Perspectiva, ed. da Universidade de São Paulo, 1974.

HISSA, Cássio E. Viana. Transdiciplinaridade e ecologia dos saberes [Entrevista]. In: HISSA, 


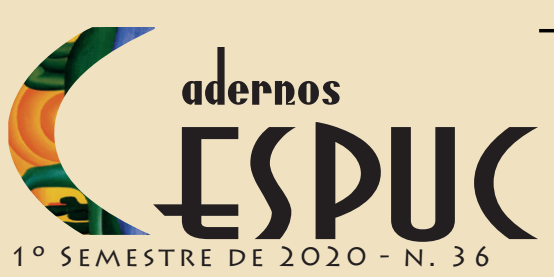

\section{Jerterson Ubiratan de Araũjo mideiros}

Cássio (org.) Conversações: de artes e ciências. Belo Horizonte: Editora da UFMG, 2011.

JACOB, François. A lógica da vida: uma história da hereditariedade. Tradução de Ângela Loureiro de Souza. Rio de Janeiro: Edições Graal, 1983.

MEDEIROS, Jefferson Ubiratan de Araújo. Epistemologias do sul nas vozes ininteligíveis e nos infinitos silêncios orais de Rap global. Dissertação (Mestrado). Programa de Pós-graduação em Letras. Belo Horizonte, 2019. 144p.

NASCIMENTO, Milton; OLIVEIRA, Marco Antonio de. Texto e hipertexto: referência e rede no processamento discursivo. In: NEGRI, Ligia; FOLTRAN, Maria José; OLIVEIRA, Roberta Pires de (org.). Sentido e significação: em torno da obra de Rodolfo Ilari. São Paulo: editora Contexto, 2004.

OESTE, Queni N. S. L. [SANTOS, Boaventura de Souza]. Rap Global. Rio de Janeiro: Aeroplano, 2010. (Coleção Tramas Urbanas)

ORUKA, H. Odera. Quatro tendências da atual Filosofia Africana. Tradução de Sally Barcelos Melo [para uso didático]. ORUKA, H. Odera. Four trends in current African philosophy. In: COETZEE, Peter H.; ROUX, Abraham P.J. (eds). The African Philosophy Reader. New York: Routledge, 2002.

RUI, Manuel. A casa do rio. Editorial Caminho, SA, Lisboa. 2007. [Coleção outras margens: autores estrangeiros de língua portuguesa]

SANTOS, Boaventura de Sousa. Para um novo senso comum: a ciência, o direito e a política na transição paradigmática, v.1, A crítica da razão indolente: contra o desperdício da experiência. 4. ed. - São Paulo: Cortez, 2002.

SANTOS, Boaventura de Souza. Apresentação. In: Rap Global. Rio de Janeiro: Aeroplano, 2010a.

SANTOS, Boaventura de Souza. A gramática do tempo: para uma nova cultura política. 3. ed. São Paulo: Cortez, 2010b. (Coleção para um novo senso comum; v. 4)

SANTOS, Boaventura de Souza. O fim do império cognitivo - A afirmação das epistemologias do Sul. Coimbra: Almedina S. A., 2018.

TALMY, L. Fictive motion in Language and "Ception". In: BLOOM, P; PETERSON, M. A.; GARRETT, M. F. Language and Space. MIT Press: Cambridge, 1996.

WALTY, Ivete. Le Langage Brésil - le langage américain: de quoi s'agit-il? Revista Ipotesi, [S.1.], v.22, n.1, p. 58-69, jan./jun. 2018. ISSN: 1982-0836. Disponível em: < https://ipotesi. ufjf.emnuvens.com.br/ipotesi/article/view/1283/785>. Acesso em: 14 fev. 2019. 